\title{
Measuring the Dielectric Constant of Paper Using a Parallel Plate Capacitor
}

Preliminary Communication

\author{
Vanja Mandrić Radivojević \\ Josip Juraj Strossmayer University of Osijek, \\ Faculty of Electrical Engineering, Computer Science and Information Technology Osijek, Croatia \\ vanja.mandric@ferit.hr
}

\author{
Slavko Rupčić \\ Josip Juraj Strossmayer University of Osijek, \\ Faculty of Electrical Engineering, Computer Science and Information Technology Osijek, Croatia \\ slavko.rupcic@ferit.hr
}

\section{Mario Srnović}

Josip Juraj Strossmayer University of Osijek, Faculty of Electrical Engineering, Computer Science and Information Technology Osijek, Croatia mario.srnovic@ferit.hr

\section{Goran Benšić}

Mechanical Engineering School of Osijek, Croatia ured@ss-strojarska-tehnicka-os.skole.hr

\begin{abstract}
This article is a result of measuring the dielectric constant of a dielectric used in studying the influence of dielectrics on the antennae reflection coefficients. A paper having a density of $0.797 \mathrm{~g} / \mathrm{cm} 3$, moisture content of $0 \%$ and temperature of $210 \mathrm{C}$, is used as a dielectric. Although the literature provides a lot of data on the dielectric properties of wood and paper, without direct measurement of the dielectric constant it is impossible to know its amount for the dielectric used in the defined frequency range. Dielectric constant measurements are performed in the frequency range from $100 \mathrm{~Hz}$ to $100 \mathrm{kHz}$, while the frequency range of its impact on the aperture antenna reflection coefficients is up to $2 \mathrm{GHz}$. The frequency range from $100 \mathrm{KHz}$ to $10 \mathrm{GHz}$ is interpolated and fitted by using measurements and available literature data and by respecting physical influences and phenomena and functional changes of the dielectric constant of paper within the given range.
\end{abstract}

Keywords - dielectric constant, loss factor, parallel plate method, dielectric constant measurement

\section{INTRODUCTION}

Paper is made from mechanically treated wood so that water can penetrate, soften the fibers and make them more flexible. This wood processing splits and frays the fibers, producing microscopic fibers that contribute to the density and tensile strength of the manufactured paper [2]. The electrical parameters of paper depend on a large number of paper parameters: wood types and paper production methods, density, humidity, temperature and frequency. Each of these parameters can take a large range of values resulting in a large range and dispersion of electrical parameters of paper.

The earliest study dealing with the dielectric properties of the material was conducted by Debye in 1929, in which he introduces the term polar dielectrics [1]. One of the earlier measurements and studies of the dielectric properties of wood was carried out by Skaar in 1949 [2]. In this paper, we present that the dielectric constant of wood increases as the moisture content increases, and it decreases with increasing frequency of the applied field. In 1953, Kroner and Pungs [3] determined that the loss tangent depends on the moisture content and had a complex form.

Further studies (by James in 1975 [4], Gaikwad in 1981 [5], Torgovnikov in 1993 [6] and Kempf in 1997 [7]) dealt with various influences on the dielectric characteristics of the material (moisture, additions, material density, structural directions, frequency, temperature, etc.) and showed that these variables also have an important influence on the dielectric behavior of wood.

Dielectric constant measurement methods cover a number of studies and research. We would like to emphasize the following: Grove in 2004 [8] (Determining 
dielectric constants using a parallel plate capacitor); Venkatesh in 2005 [9]; Ganchev in 2006 [10] and Tereshchemko et al. in 2011. The main objective of this paper is to use parallel plate methods of measurement and different models and methods of calculating dielectric parameters and dielectric losses and their applicability to different materials.

A large number of studies have been carried to determine the dielectric constant of wood and paper, e.g. physical testing of paper [11] by Mark et al. in 2001 dealing with the dielectric constant of papers and different cellulosic materials. Studies by Sirvio [12] and Omari [13] in 2016 provide research and measurement of different types of paper for a number of new applications.

In this paper, we used the parallel plate method for measuring the dielectric constant of paper which involves placing a paper sample between two capacitor plates and measuring the resulting capacitance and other parameters used an equivalent capacitor model such as equivalent serial inductance, equivalent serial and parallel resistance, dissipation factor $D=\tan \delta$, the angle between the current and the voltage $\theta$ and capacitor $\mathrm{Q}$ factor.

In addition, linear interpolation of results available from literature is derived for the frequency range from $100 \mathrm{~Hz}$ to $10 \mathrm{GHz}$.

\section{THE DIELECTRIC CONSTANT (PERMITTIVITY)}

The dielectric constant is equivalent to relative permittivity $\varepsilon$ r or absolute permittivity $\varepsilon$ relative to permittivity of free space $\varepsilon 0$. The dielectric constant is generally a complex number which describes the interaction of a material with an electric field:

$$
\begin{gathered}
\varepsilon=\varepsilon^{\prime}-j \varepsilon^{\prime \prime}=\varepsilon^{\prime}(1-j \tan \delta)=|\varepsilon| e^{-j \delta}, \\
\varepsilon^{\prime}=\varepsilon_{r} \varepsilon_{0}, \\
\varepsilon^{\prime \prime}=\varepsilon^{\prime} \tan \delta,
\end{gathered}
$$

where $\varepsilon^{\prime}$ is a real part of the dielectric constant or relative dielectric constant;

$$
\begin{aligned}
& \varepsilon^{\prime \prime} \text { is an imaginary part of the dielectric } \\
& \text { constant or dielectric loss factor; }
\end{aligned}
$$

$\delta$ is a dielectric loss angle (Fig. 2a); and

$\tan \delta$ is loss tangent or the dissipation factor DF.

The dissipation factor is often used interchangeably with the term power factor which is approximately equal (Fig.2).

For a good dielectric $\varepsilon^{\prime \prime}<\varepsilon^{\prime}$ (Fig. 2b):

$$
\cos \theta \approx \tan \delta=\frac{\varepsilon^{\prime \prime}}{\varepsilon^{\prime}}=\frac{\text { energy loss per cycle }}{\text { energy stored per cycle }} .
$$

The real part of the complex dielectric constant $\varepsilon^{\prime}$ is a measure of how much energy from an external field is stored in a material.

The imaginary part of the complex dielectric constant $\varepsilon^{\prime \prime}$ is a measure of how dissipative or lossy a material is to an external field. The dielectric loss angle $\delta$ is the angle between the real part of the dielectric constant and the absolute value of the dielectric constant, and the loss tangent $\tan \delta$ is defined as the ratio of the imaginary part to the real part of the complex dielectric constant (Fig. 1) [14].

The dielectric constant $\varepsilon$ is not constant by changing either the frequency or the temperature. Frequency dependence is important for the considerations and analyses performed for the purpose of this paper.

One of the most important intrinsic properties of paper as a dielectric material associated with the frequency is its polarization ability. Polarization is a quantity which characterizes the material polarization effect under the influence of the external electric field. The polarization effect is caused by the change in the spatial arrangement of electrically charged particles of the wood substance under the influence of an external electric field that changes with time and excites an alternating electric current in the wood (paper) (Fig. 2).

Under this condition, wood (paper) acquires an electric moment [6].

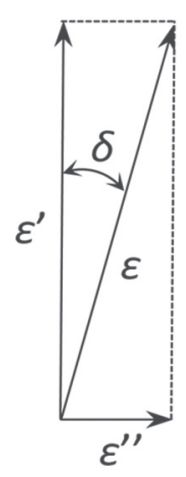

a)

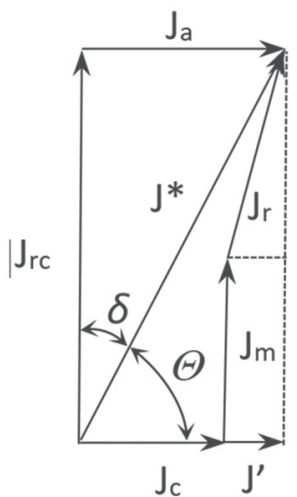

b)
Fig. 1. a) Vector diagram of the complex dielectric constant $\varepsilon$; b) Vector schematic diagram of currents in wood under the action of an external alternating current field E: $J^{*}$ - total current; J active component of the current; $J_{\mathrm{rc}}$ - reactive component of the current;

$\mathrm{J}_{\mathrm{e}}$ - conduction current; $\mathrm{J}_{\mathrm{m}}$ - instant displacement current; Jr - relaxation displacement current; J' - active component of the displacement current; $\delta$ - dielectric loss angle; $\theta$ - phase displacement angle [6].

The geometric sum of the electric field strength vector at a given point of the dielectric multiplied by the electric constant and of the polarization vector gives the electric displacement (electric induction) vector $D$ at this point [11]: 


$$
\vec{D}=\varepsilon_{0} \vec{E}+\vec{P},
$$

where $\vec{E}$ is electric field strength;

$$
\begin{aligned}
& \vec{P} \text { is polarization of the material; and } \\
& \varepsilon_{0} \text { is the dielectric constant of vacuum. }
\end{aligned}
$$

The connection between the relative dielectric constant and the polarization of the material is as follows:

$$
\vec{P}=\left(\varepsilon^{\prime}-1\right) \varepsilon_{0} \vec{E},
$$

where $\varepsilon^{\prime}$ is the relative dielectric constant of the material.

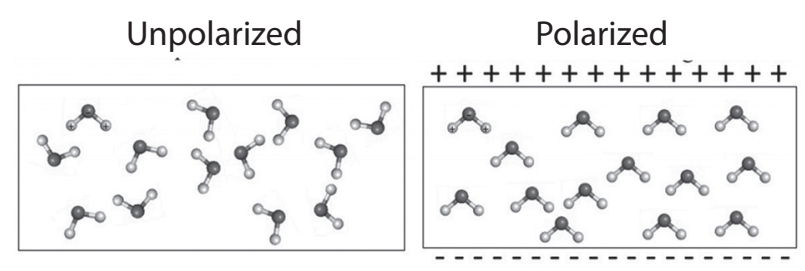

Fig. 2. Representation of material polarization in the presence of an EM field [15].

Summary polarization of wood (and paper as well) P, includes five kinds of polarization, which take place in moist heterogeneous dielectrics (Fig. 3):

$$
P=P_{e}+P_{a}+P_{d}+P_{v}+P_{z} .
$$

Electronic polarization $P_{e}$ arises as a result of the shift of electron orbits relative to the positively charged nucleus under the influence of an external electric field.

Ionic (atomic) polarization $P_{a}$ arises as a result of an elastic displacement of atoms in the molecules as well as due to a mutual displacement of charged ions of opposite signs in substances with ionic bonds.

Dipole (orientational) polarization $P_{d}$ consists of the rotation of dipole molecules in the direction of an external electric field.

Upon application of an electric field to heterogeneous dielectrics, free electrons and ions start moving within each element's volume, and as a result, the element receives a dipole moment -> interfacial polarization $P_{v}$.

The material always has residual electrochemical or electrolytic polarization. At the instant of imposition of an electric field, an increase in electrolytic polarization $P_{z}$ is observed. The increase of this kind of polarization is much slower than that of other types of polarization considered above. Electrolytic polarization of wood can be characterized by its time constant, which is approximately equal to $10^{-4}-10^{2} \mathrm{sec}$. [6].

The contribution of different kinds of polarization to the $\varepsilon^{\prime}$ value is as follows: $\varepsilon_{e}^{\prime}$ - electronic polarization deposit; $\varepsilon_{a}^{\prime}$ - ionic (atomic) polarization deposit; $\varepsilon_{d}^{\prime}$ - dipole polarization deposit; $\varepsilon_{v}^{\prime}$ - interfacial polarization deposit; $\varepsilon_{z}^{\prime}$ - electrolytic polarization deposit; lgf - logarithm of frequency value [6].

If the relaxation time $\tau$ of dipoles of the dielectric is the same, then the connection between the complex dielectric constant and the frequency is to be found from the Debye equation:

$$
\varepsilon=\varepsilon_{\infty}^{\prime}+\left(\varepsilon_{s}^{\prime}-\varepsilon_{\infty}^{\prime}\right) /(1+j \omega \tau),
$$

where $\varepsilon_{\infty}^{\prime}$ is the limiting high-frequency relative dielectric constant;

$\varepsilon_{s}^{\prime}$ the limiting low-frequency relative dielectric constant (static);

$\omega$ the angular frequency; and

$\tau$ the macroscopic time of relaxation [6].

The polarization process depends on the time $t$ as follows:

$$
P=P_{0} e^{-t / \tau}
$$

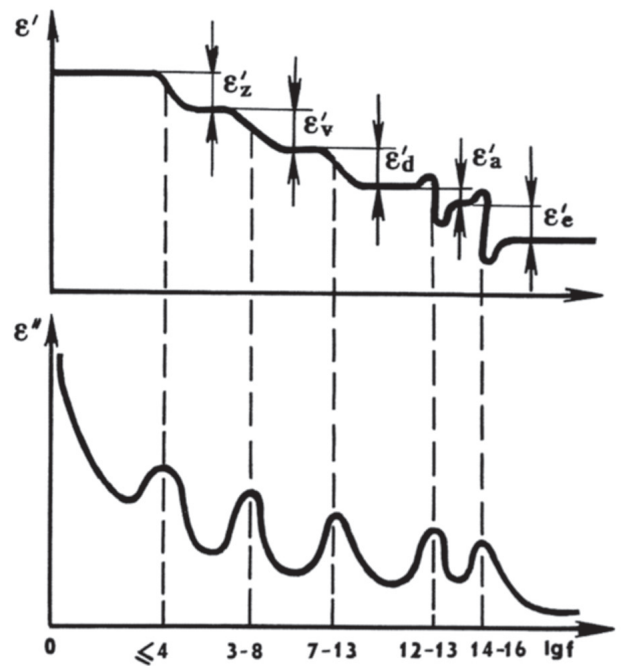

Fig. 3. Vector schematic diagram of dielectric constant $\varepsilon^{\prime}$ and loss factor $\varepsilon^{\prime \prime}$ of wood versus frequency response characteristics with different kinds of polarization [6].

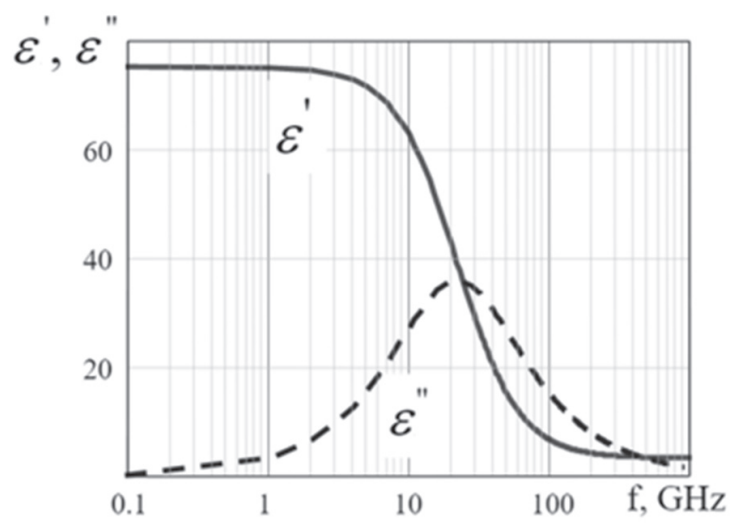

Fig. 4. Debye relaxation equation (8) for water at $30^{\circ} \mathrm{C}[10]$. 
The resonant frequency $f$ is identified by a resonant response in $\varepsilon^{\prime}$ and a peak of maximum absorption in $\varepsilon^{\prime \prime}$ $\left(f_{c}=22 \mathrm{GHz}\right.$ for water at $30^{\circ} \mathrm{C}$ in Fig. 4).

Figure 4 presents a dashed part of the diagram in Figure 3. It is focused on this dielectric constant measurement and interpolation.

\section{PARALLEL PLATE METHOD - CAPACITOR METHOD}

The measurement methods of dielectric material properties depend on physical and electrical parameters of the dielectric material to be measured, the frequency of interest, and the degree of accuracy required. The summary of techniques for measuring the dielectric properties of materials are presented in Table 1.

The parallel plate method uses a parallel plate capacitor as a sample holder and auxiliary parameter being measured, with the material under the measurement between plates. This method requires instruments for measuring capacitor impedance (LCR meter) or an impedance analyzer. The measured capacitance and dissipation factor is then used to calculate the real and imaginary parts of the dielectric constant. By using this method, all parameters of the equivalent model shown in Figure 5 were measured $\left(L_{s^{\prime}} R_{s^{\prime}} C_{p}\right.$ and $\left.R_{p}\right)$. In addition, measurements included measurement of the dissipation factor $\mathrm{D}=\tan \delta$, the angle between the current and the voltage $\theta$ and the capacitor Q factor (Figures 4 to 6).

Table 1. Summary of techniques for measuring the dielectric properties of materials [16].

\begin{tabular}{|c|c|c|c|c|}
\hline Method & 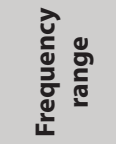 & 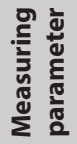 & Figure & $\begin{array}{l}\text { Character- } \\
\text { istics and } \\
\text { applications }\end{array}$ \\
\hline $\begin{array}{l}\text { Parallel } \\
\text { plate }\end{array}$ & $\begin{array}{l}\text { up to } 1.8 \\
\mathrm{MHz}^{*}\end{array}$ & $\varepsilon_{\mathrm{r}}$ & & $\begin{array}{l}\text { Accurate, best } \\
\text { for low frequen- } \\
\text { cies flat, thin } \\
\text { sheet }\end{array}$ \\
\hline $\begin{array}{l}\text { Coaxial } \\
\text { probe }\end{array}$ & $\begin{array}{c}100 \mathrm{MHz} \\
\text { to } 50 \mathrm{GHz}\end{array}$ & $\varepsilon_{\mathrm{r}}$ & & $\begin{array}{l}\text { Broadband best } \\
\text { for lossy mat., } \\
\text { liquids or semi- } \\
\text { solids }\end{array}$ \\
\hline $\begin{array}{l}\text { Transmis- } \\
\text { sion line }\end{array}$ & $\begin{array}{c}100 \mathrm{MHz} \\
\text { to } 60 \mathrm{GHz}\end{array}$ & $\varepsilon_{r^{\prime}} \mu_{r}$ & & $\begin{array}{l}\text { Broadband } \\
\text { best for lossy to } \\
\text { low lossy mat., } \\
\text { machine able } \\
\text { solids }\end{array}$ \\
\hline $\begin{array}{l}\text { Free } \\
\text { space }\end{array}$ & $\begin{array}{l}1 \mathrm{GHz} \text { to } \\
100 \mathrm{GHz}\end{array}$ & $\varepsilon_{r^{\prime}} \mu_{r}$ & & $\begin{array}{l}\text { Broadband } \\
\text { Non-contacting } \\
\text { best for high } \\
\text { temp., large, flat } \\
\text { samples }\end{array}$ \\
\hline $\begin{array}{l}\text { Resonant } \\
\text { cavity }\end{array}$ & $\begin{array}{l}3 \mathrm{GHz} \text { to } \\
30 \mathrm{GHz}\end{array}$ & $\varepsilon_{r^{\prime}} \mu_{r}$ & & $\begin{array}{c}\text { Accurate, best } \\
\text { for low loss mat., } \\
\text { small samples, } \\
\text { substrates, thin } \\
\text { films }\end{array}$ \\
\hline
\end{tabular}

The method uses a frequency range up to $1.8 \mathrm{GHz}$, has high measurement accuracy and involves a very simple sample preparation and setup. This method is also best for thin flat sheets of samples. The dielectric constant is derived by knowing the dimensions of the material and plates (width, length, thickness) and by measuring its capacitance and dissipation factor.

The dielectric constant is calculated as follows:

$$
\varepsilon^{\prime}=\frac{t_{d} \cdot C_{p}}{S \cdot \varepsilon_{0}},
$$

where $t_{\mathrm{d}}$ is the average thickness of sample $(\mathrm{m}), \mathrm{S}$ is guarded electrode's surface area $\left(\mathrm{m}^{2}\right), \varepsilon_{0}$ stands for permittivity of free space $\left(8.854 \times 10^{-12} \mathrm{~F} / \mathrm{m}\right)$, and $C p$ corresponds to the equivalent parallel capacitance of sample (F) [13].

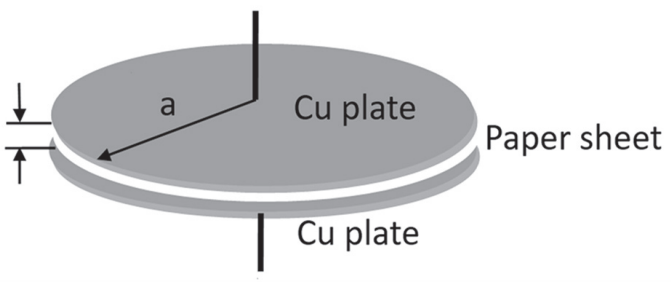

a)

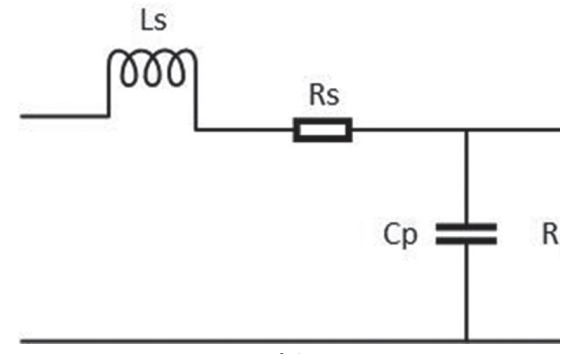

b)

Fig. 5. a) Parallel plate capacitor with paper as a dielectric (the diameter of the plates $2 a$ is $20 \mathrm{~cm}$ ); b) an equivalent circuit for a capacitor.

In Fig. 5, $L_{s}$ is equivalent series inductance, $R_{s}$ is equivalent series resistance, $R_{p}$ is equivalent parallel resistance and $C_{p}$ is equivalent parallel capacitance.

\section{EASUREMENT AND MEASUREMENT RESULTS}

\subsection{Measurement}

The dielectric constant and the loss factor were measured by using the parallel plate method. Dielectric constant and loss factor measurements were performed as part of antenna aperture reflection coefficient measurements using different materials as radomes for this antenna [15], [17]. Thus, there was a need for information on the dielectric constant of wood and woodbased materials (paper) that are analyzed in this paper.

The weight of a sheet of paper used as a sample was $4.9719 \mathrm{~g}$ and the density of $0.797 \mathrm{~g} / \mathrm{cm}^{3}$. 
The measured value of capacitance may be thought of as two capacitors $C_{p}$ and $C_{d}$ in series; one is a perfect parallel capacitor filled with the dielectric material $C_{d}$ and the other capacitor is a perfect parallel capacitor filled with air $\mathrm{C}_{\text {air }}$ :

$$
\frac{1}{C_{\text {meas }}}=\frac{1}{C_{p}}=\frac{1}{C_{d}}+\frac{1}{C_{\text {air }}}=\frac{t_{d}}{S \cdot \varepsilon^{\prime} \varepsilon_{0}}+\frac{t_{\text {air }}}{S \cdot \varepsilon_{0}}
$$

where $t_{\mathrm{d}}$ is the thickness of the dielectric material $(\mathrm{m})$, $t_{\text {air }}$ is the thickness of unwanted air gaps (m) (Fig. 6), $S$ is the capacitor surface area $\left(\mathrm{m}^{2}\right), \varepsilon_{0}$ is the permittivity of free space $\left(8.854 \times 10^{-12} \mathrm{~F} / \mathrm{m}\right)$, and $\varepsilon^{\prime}$ is the permittivity of the dielectric material:

$$
\varepsilon^{\prime}=\left(\frac{1}{\frac{1}{C_{p}}-\frac{t_{\text {air }}}{S \cdot \varepsilon_{0}}}\right) \cdot \frac{t_{d}}{S \cdot \varepsilon_{0}}
$$

The capacitor filled with air $\left(C_{\mathrm{air}}\right)$ is an equivalent capacitor of all air gaps between capacitor plates (Fig. 6). The influence of unwanted air gaps on the total capacity as well as on the dielectric constant and the loss factor is increased with an increase in paper layers and the thickness of the dielectric (Figures 7 and 8).

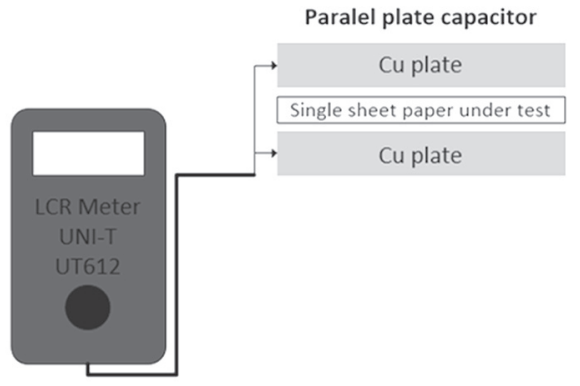

Unwanted air gaps

a)
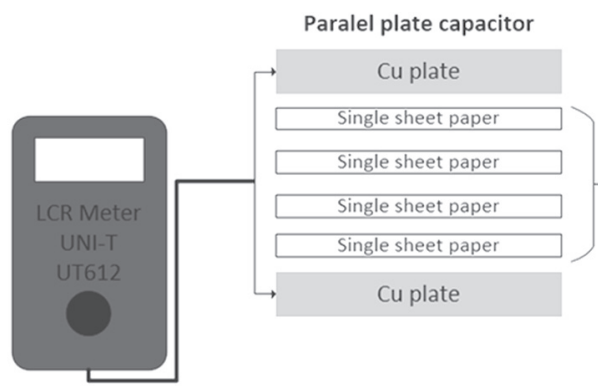

Unwanted air gaps

Multilayer

dielectric under test

b)

Fig. 6. Capacitance measurement (a) thin dielectric - single sheet paper dielectric, (b) thick multilayer dielectric.

Measurement equipment in these measurements consists of a circular shape capacitor of $8 \mathrm{~cm}$ in diameter and LRC meter UNI-T, type UT612.

Determining the dielectric constant value of paper at specific temperature and frequency range sometimes poses a problem. This problem appears when the dielectric constant and the loss factor in a given frequency range or at specific temperature are not available. In this paper, equation (8) available from literature does not help much because of frequency discrepancy between the experimental and theoretical determination and the lack of measured (precise) values of the interconstants of the particular observed sample $\left(\varepsilon_{\infty}^{\prime}\right.$ is the limiting high frequency relative dielectric constant, $\varepsilon_{s}^{\prime}$ is the limiting low frequency relative dielectric constant (static); $\tau$ is the macroscopic time of relaxation time constants, appearing in this equation [5]).

\subsection{Results from available literature}

The analysis performed in this section is based on the measurements of the dielectric constant and loss factors of wood and wood-based materials (paper) in [4], [6] and [13]. [4] deals with measured values of the dielectric constant and loss tangent of white oak, Douglas-fir, and four commercial hardboards at frequencies from $20 \mathrm{Hertz}(\mathrm{Hz})$ to 50 Megahertz $(\mathrm{MHz})$, moisture conditions from oven dry to complete saturation, temperatures from $-20^{\circ} \mathrm{C}$ to $+90^{\circ} \mathrm{C}$, and for the natural wood, with the electric field aligned with three principal structural orientations. Oven-dry wood is obtained by using the specimens originally conditioned and tested in equilibrium with 30 percent relative humidity. These specimens were dried in a vacuum oven at $60^{\circ} \mathrm{C}$. Table 2 presents the real part and loss tangent of the dielectric constant as a function of frequency for tangential oak of density $0.74 \mathrm{~g} / \mathrm{cm}^{3}$ and temperature

\begin{tabular}{|c|c|c|}
\hline Frequency & $\begin{array}{l}\text { Real part of dielec- } \\
\text { tric constant } \\
5^{\circ} \mathrm{C}-25^{\circ} \mathrm{C}\end{array}$ & $\begin{array}{c}\operatorname{Tg} \delta \\
5^{\circ} \mathrm{C}-25^{\circ} \mathrm{C}\end{array}$ \\
\hline $100 \mathrm{~Hz}$ & $2.50-2.60$ & $0.050-0.0076$ \\
\hline $1 \mathrm{kHZ}$ & $2.30-2.30$ & $0.033-0.021$ \\
\hline $10 \mathrm{kHZ}$ & $2.20-2.20$ & $0.035-0.033$ \\
\hline $100 \mathrm{kHz}$ & $2.10-2.20$ & $0.038-0.040$ \\
\hline $1 \mathrm{MHz}$ & $2.20-2.20$ & $0.047-0.046$ \\
\hline $10 \mathrm{MHz}$ & $2.10-2.20$ & $0.052-0.054$ \\
\hline
\end{tabular}
ranging between 5 and $25^{\circ} \mathrm{C}$.

Table 2. Real part and loss tangent of the dielectric constant of density $0.74 \mathrm{~g} / \mathrm{cm}^{3}$ and temperature $5-25^{\circ} \mathrm{C}[4]$.

[6] deals with dielectric parameters of wood and wood based materials.

From this reference, for the purpose of comparing measured values and, more importantly, for interpolation purposes, measured data of the dielectric constant and the loss factor for oven-dry paper of density $0.80 \mathrm{~g} / \mathrm{cm}^{3}$ and temperature $20-25^{\circ} \mathrm{C}$ with vector $\mathrm{E}$ oriented perpendicularly to the sheet surface, were used. 
The frequency range of the dielectric constant and the loss factor is from $100 \mathrm{~Hz}$ to $10 \mathrm{GHz}$. The term oven-dry wood (or paper) implies wood dried to a constant mass in the air at a temperature equal to $+103 \pm 2{ }^{\circ} \mathrm{C}$ [6].

Using the data from the above reference, the interpolation of the dielectric constant value and the loss factor for the frequency range above the measurement range was performed.

Table 3 presents measured values of the dielectric constant and the loss factor for oven-dry paper of density $0.80 \mathrm{~g} / \mathrm{cm}^{3}$ and temperature $20-25^{\circ} \mathrm{C}$ with vector $\mathrm{E}$ oriented perpendicularly to the sheet surface based on data from [6].

From [13], which deals with the dielectric constant of paper made of pulp of several materials based on natural products, the values of the dielectric constant and the factor of losses for agave paper were used. The agave (agave americana) hand sheets were prepared according to a standard papermaking method (TAPPI T205 sp-954). This paper sheet is heterogeneous (cellulose, lignin, fines, and other impurities related to extraction processes of fibers and the origin of the plant) and hydrophilic, with rough surfaces and consequently a lack of flatness, necessary for a good contact with the electrodes [13].

Table 3. The dielectric constant and the loss factor of oven-dry paper as a function of frequency with density $0.80 \mathrm{~g} / \mathrm{cm} 3$ and temperature $20-250 \mathrm{C}$ with vector $\mathrm{E}$ oriented perpendicularly to the sheet surface [6].

\begin{tabular}{|c|c|c|c|}
\hline Frequency & $\begin{array}{c}\varepsilon^{\prime} \\
20^{\circ} \mathrm{C}-25^{\circ} \mathrm{C}\end{array}$ & $\begin{array}{c}\operatorname{Tg} \delta \\
20^{\circ} \mathrm{C}-25^{\circ} \mathrm{C}\end{array}$ & $\begin{array}{l}\varepsilon^{\prime \prime}=\varepsilon^{\prime} \cdot \operatorname{tg} \delta \\
20^{\circ} \mathrm{C}-25^{0} \mathrm{C}\end{array}$ \\
\hline 100 & $1.80-3.30$ & $0.0030-0.012$ & $0.0054-0.0396$ \\
\hline $1 \mathrm{kHz}$ & $1.80-3.30$ & $0.0030-0.015$ & $0.0054-0.0495$ \\
\hline $10 \mathrm{kHz}$ & $1.80-3.20$ & $0.0044-0.021$ & $0.0079-0.0672$ \\
\hline $100 \mathrm{kHz}$ & $1.80-3.10$ & $0.0067-0.031$ & $0.01206-0.0961$ \\
\hline $1 \mathrm{MHz}$ & $1.80-3.00$ & $0.010-0.043$ & $0.0180-0.1290$ \\
\hline $10 \mathrm{MHz}$ & $1.80-2.80$ & $0.014-0.053$ & $0.0252-0.1484$ \\
\hline $100 \mathrm{MHz}$ & $1.70-2.60$ & $0.013-0.046$ & $0.0221-0.1196$ \\
\hline $1 \mathrm{GHz}$ & $1.60-2.20$ & $0.011-0.032$ & $0.0176-0.0704$ \\
\hline $10 \mathrm{GHz}$ & $1.60-2.10$ & $0.011-0.030$ & -0.0630 \\
\hline
\end{tabular}

A variation of the dielectric constant and loss factors with frequency for different papers are represented in Table 4.
Table 4. Real and imaginary parts of the dielectric constant as a function of frequency for agava americana paper with a hand sheet characteristic: hand sheet weight: $1.23 \mathrm{~g}$, fines content: $46.55 \%$, average fiber length: $0.52 \mathrm{~mm}$, porosity: $7637 \mathrm{~mL} /$ min, roughness: $10.93 \mu \mathrm{m}$, crystallinity rate: $44.05 \%$ and young modulus: $715.50 \mathrm{MPa}$ [13].

$\begin{array}{ccc}\text { Frequency } & \begin{array}{c}\text { Real part of } \\ \text { dielectric constant }\end{array} & \begin{array}{c}\text { Imaginary part of } \\ \text { dielectric constant }\end{array} \\ 100 \mathrm{~Hz} & 2.77 & 0.99 \\ 1 \mathrm{kHZ} & 2.50 & 0.33 \\ 10 \mathrm{kHZ} & 2.20 & 0.15 \\ 100 \mathrm{kHz} & 2.00 & 0.09 \\ 1 \mathrm{MHz} & 1.80 & 0.06 \\ 10 \mathrm{MHz} & 0.80 & 0.01\end{array}$

The dielectric measurements were carried out at room temperature with an impedance meter (Agilent4294A) using a cell (Agilent 16451B) allowing direct measurement. The frequency range was between $100 \mathrm{~Hz}$ and $10 \mathrm{MHz}$. The samples were dried in an oven at $105^{\circ} \mathrm{C}$ to remove residual water [13]. The dielectric constant is calculated by using equation (10).

\subsection{Measurement results and interpolatione}

The standard SMART LINE OFFICE A4, $80 \mathrm{~g} / \mathrm{m}^{2}$, MONDI paper was used as a sample paper for measurement. There are no information on dielectric properties for this paper. Since there is an extremely large number of different types of paper with different parameters, it was not possible to find information about the paper used. Measurements were made with the available equipment and they provided the measured data. Measurements were performed as part of measurements done for the antenna aperture reflection coefficient using paper as a radome for this antenna. The frequency range of the used aperture antenna is significantly greater than the scope of measurement and for that range of the frequency band the interpolation of the data from literature complies with the measured data.

Wood is a raw material for paper building. An oak sample was used in [4] to determine the dielectric constant and loss factors. The dielectric constant and the loss factor of paper used in these measurements and oak were compared [4] (with similar parameters, i.e. humidity, density and temperature), as illustrated in Fig. 9. It is evident that the dielectric properties of these two materials are very similar.

In the second part, the results obtained by using measurements of the dielectric constant and the loss factor of paper are compared with experimental values from [6] and [13] and presented in Fig. 10 and Fig. 11. 
Figure 10 shows measured values of the dielectric constant and loss factors together with literature data [6] for paper of the same density, i.e. $0.8 \mathrm{~g} / \mathrm{m}^{3}$. Measurement of dielectric parameters is performed in the frequency range from $10^{2}$ to $10^{5} \mathrm{~Hz}$, while the data from literature cover the full range of frequencies $\left(10^{2}\right.$ $-10^{10} \mathrm{~Hz}$ ). The data from 6 were interpolated for the approximate temperature at which measurements were performed $\left(21.3^{\circ} \mathrm{C}\right)$ and compared with the measurements. For the purpose of comparing data to the extent not covered by the measurements, measured data are fitted using the exponential function (equation (13)).

In this diagram, it can be seen that measured (and fitted) data of the real part of the dielectric constant, using the parallel plate method, are very close to the values mentioned in the references. It is therefore assumed that for the non-available frequency band the extrapolation of known values can be interpolated while maintaining the same conditions and parameters of the materials used.

The same procedure is performed for the data shown in Fig. 11, only by using the interpolated data of the previous analysis. The reason is that there is no data interpolated frequency band in [13].

What is still remarkable is that measured data on the dielectric constant and the loss factor of the measured paper and paper derived from the agave match very well, but there is a visible discrepancy in the curve passing through measured data and showing an exponential tendency to "saturation" and maintaining a constant value in the frequency range from $10^{5}$ to $10^{10} \mathrm{~Hz}$.

Table 5. Measured values of equivalent capacitor circuit parameters as a function of frequency for a paper dielectric sheet of density $0.797 \mathrm{~g} / \mathrm{cm}^{3}$ (for a $5 \mathrm{~g}$ paper sheet) and temperature $21^{\circ} \mathrm{C}$.

\begin{tabular}{|c|c|c|c|c|c|c|}
\hline $\begin{array}{c}\text { Paper } \\
\text { thickness }\end{array}$ & & & & & & 0 \\
\hline $\begin{array}{c}f \\
{[k H z]}\end{array}$ & $\begin{array}{l}\text { Cp } \\
{[p F]}\end{array}$ & D & $\begin{array}{c}\text { Cp } \\
{[p F]}\end{array}$ & D & $\begin{array}{c}\text { Cp } \\
{[p F]}\end{array}$ & D \\
\hline 0.1 & 7932.0 & 0.214 & 911.0 & 0.219 & 166.0 & 0.392 \\
\hline 1 & 6631.0 & 0.095 & 764.6 & 0.094 & 114.5 & 0.205 \\
\hline 10 & 6125.0 & 0.041 & 707.2 & 0.042 & 96.4 & 0.087 \\
\hline 100 & 5878.0 & 0.023 & 678.8 & 0.023 & 88.2 & 0.049 \\
\hline
\end{tabular}

Table 6 presents linear interpolated values of the dielectric constant and the loss factor of oven-dry paper of density $0.80 \mathrm{~g} / \mathrm{cm}^{3}$ and temperature $21.3^{\circ} \mathrm{C}$ with vector $\mathrm{E}$ oriented perpendicularly to the sheet surface based on data from [6]. The interpolation is derived for the data from Table 3 for temperature $21.3^{\circ} \mathrm{C}$.
Table 6. Interpolated values of the dielectric constant and the loss factor as a function of frequency for oven-dry paper of density $0.80 \mathrm{~g} /$ $\mathrm{cm}^{3}$ and temperature $21.3^{\circ} \mathrm{C}$ with vector E oriented perpendicularly to the sheet surface [6].

\begin{tabular}{cccc} 
Frequency & $\boldsymbol{\varepsilon}^{\prime}$ & $\operatorname{tg} \delta$ & $\boldsymbol{\varepsilon}^{\prime \prime}=\boldsymbol{\varepsilon}^{\prime} \cdot \mathbf{t g} \boldsymbol{\delta}$ \\
\hline $10 \mathrm{~Hz}$ & 2.19 & 0.00534 & 0.01169 \\
\hline $1 \mathrm{kHz}$ & 2.10 & 0.01860 & 0.03906 \\
\hline $10 \mathrm{kHz}$ & 2,06 & 0.00872 & 0.01799 \\
\hline $100 \mathrm{kHz}$ & 2.14 & 0.006084 & 0.01302 \\
\hline $1 \mathrm{MHz}$ & 2.11 & 0.008806 & 0.01858 \\
\hline $10 \mathrm{MHz}$ & 2.06 & 0.011718 & 0.02414 \\
\hline $100 \mathrm{MHz}$ & 1.93 & 0.011181 & 0.02158 \\
\hline $1 \mathrm{GHz}$ & 1.76 & 0.009352 & 0.01646 \\
\hline $10 \mathrm{GHz}$ & 1.73 & 0.009139 & 0.01594 \\
\hline
\end{tabular}

Table 7. Interpolated values of the dielectric constant and the loss factor as a function of frequency of tangential oak, the dielectric constant and loss tangent of density $0.74 \mathrm{~g} / \mathrm{cm}^{3}$ and temperature $21^{\circ} \mathrm{C}$ [4].

\begin{tabular}{cccc} 
Frequency & $\boldsymbol{\varepsilon}^{\prime}$ & $\operatorname{tg} \delta$ & $\boldsymbol{\varepsilon}^{\prime \prime}=\boldsymbol{\varepsilon}^{\prime} \cdot \operatorname{tg} \boldsymbol{\delta}$ \\
\hline $100 \mathrm{~Hz}$ & 2.58 & 0.18318 & 0.47260 \\
\hline $1 \mathrm{kHz}$ & 2.30 & 0.04370 & 0.10051 \\
\hline $10 \mathrm{kHz}$ & 2,20 & 0.07260 & 0.15972 \\
\hline $100 \mathrm{kHz}$ & 2.18 & 0.08720 & 0.19009 \\
\hline $1 \mathrm{MHz}$ & 2.20 & 0.10120 & 0.22264 \\
\hline $10 \mathrm{MHz}$ & 2.18 & 0.11554 & 0.25188 \\
\hline
\end{tabular}

Table 7 presents linear interpolated values of the dielectric constant and the loss factor of tangential oak, the dielectric constant and loss tangent of density 0.74 $\mathrm{g} / \mathrm{cm}^{3}$ and temperature $21^{\circ} \mathrm{C}$.

The parallel plate method is suitable for thin dielectrics and deviations and errors due to unwanted air gaps are the smallest in the dielectric constant and loss factors for dielectric thickness of $0.1 \mathrm{~mm}$.

Therefore, if the values of the real and the imaginary part of the dielectric constant of the tiny dielectric ( 0.1 $\mathrm{mm}$ ) are taken as a reference, the deviations and errors of these parameters at two thicknesses ( 1 and $10 \mathrm{~mm}$ ) can be determined. These errors are listed in Table 8 .

It can be seen that the relative error of the dielectric constant increases with increasing of the dielectric thickness, i.e. an increase in unwanted air gaps as well 
as the dispersion of the electric field outside the space between the capacitor plates.

Table 8. Relative errors of the real and the imaginary part of the dielectric constant with the dielectric parameters of smallest thickness dielectric $(0.1 \mathrm{~mm})$ as a reference.

\begin{tabular}{|c|c|c|c|c|c|c|}
\hline \multirow{2}{*}{$\begin{array}{l}\text { Freq. } \\
\underset{t_{d}}{m m}\end{array}$} & \multicolumn{2}{|c|}{$1 \mathrm{kHz}$} & \multicolumn{2}{|c|}{$10 \mathrm{kHz}$} & \multicolumn{2}{|c|}{$100 \mathrm{kHz}$} \\
\hline & $\begin{array}{c}\text { Real Err } \\
\%\end{array}$ & $\begin{array}{c}\text { Ima } \\
\text { Err } \\
\%\end{array}$ & $\begin{array}{c}\text { Real }_{\text {Err }} \\
\%\end{array}$ & $\underset{\%}{\text { Ima }_{\text {Err }}}$ & $\begin{array}{c}\text { Real Err } \\
\%\end{array}$ & ${ }_{\%}^{\text {Ima }}$ \\
\hline 0.1 & $-1 ., 49$ & -62.93 & -22.81 & -85.21 & -25.96 & -92.043 \\
\hline 1 & -16.16 & -64.01 & -22.56 & -85.15 & -25.61 & -92.1871 \\
\hline 10 & -30.99 & -63.91 & -42.04 & -87.14 & -46.90 & -93.3626 \\
\hline
\end{tabular}

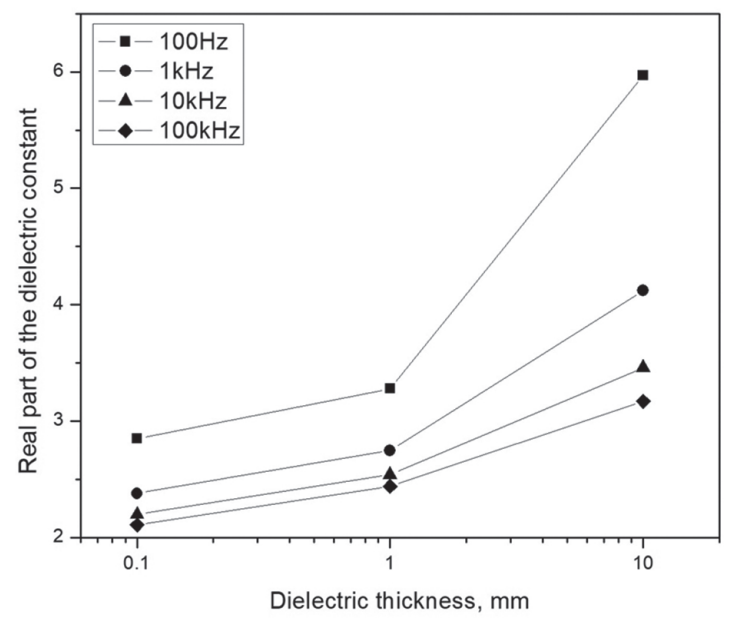

Fig. 7. A plot of the real part of the dielectric constant versus the dielectric thickness for paper sheet with density $0.797 \mathrm{~g} / \mathrm{cm}^{3}$ at $21^{\circ} \mathrm{C}$ calculated using equations (10) and (3) from measured values presented in Table 5.

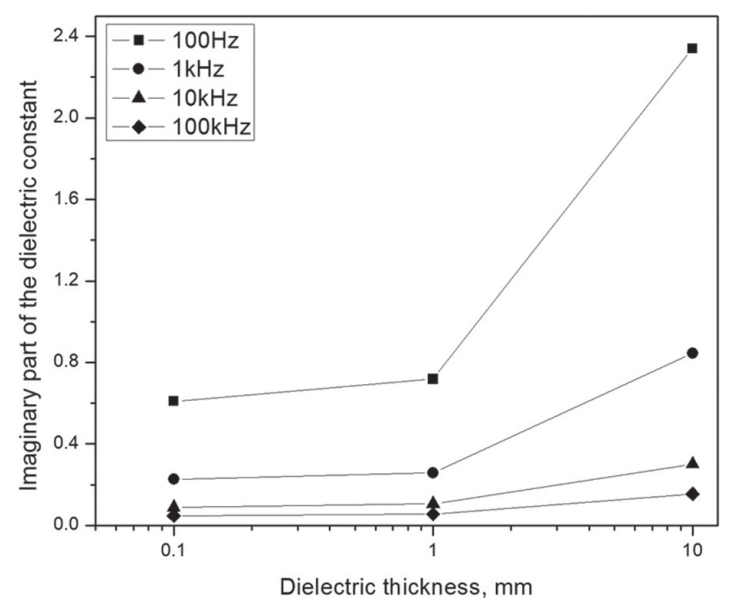

Fig. 8. A plot of the imaginary part of the dielectric constant versus the dielectric thickness for paper sheet with density $0.797 \mathrm{~g} / \mathrm{cm}^{3}$ at $21^{\circ} \mathrm{C}$ calculated using equations (10) and ( 3 ) from measured values presented in Table 5.

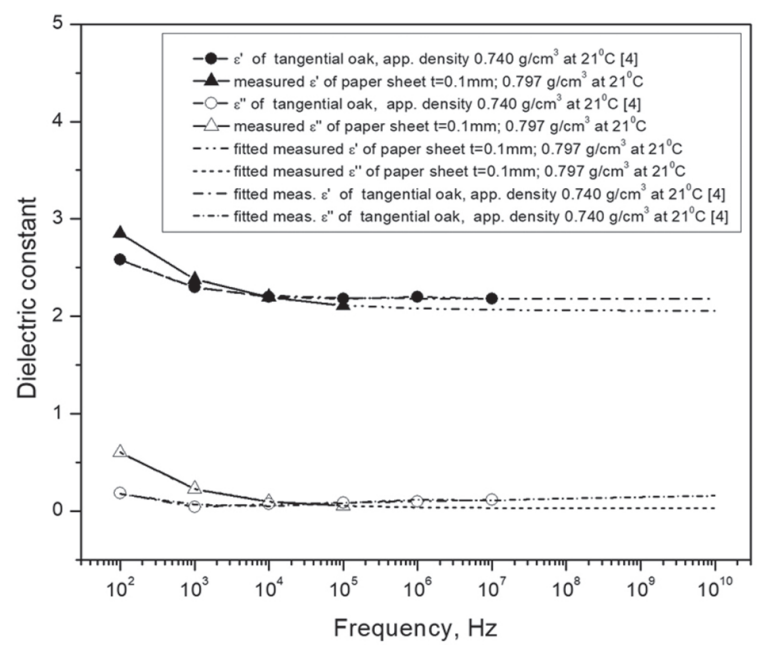

Fig. 9. Measured, linear interpolated and fitted dielectric constant (real and imaginary part) as a function of frequency for $0.1 \mathrm{~mm}$ paper sheet and measured dielectric constant of oak (tangential) [4].

The number and size of unwanted air gaps are too large for a large number of paper sheets to cause significant errors when using the parallel plate method. Therefore, a single sheet of paper was taken as relevant, and the results of the comparison with the measured values in the literature confirm this claim. The measured values of the dielectric constant and the loss factor when compared with the measurements in the literature show good value matching.

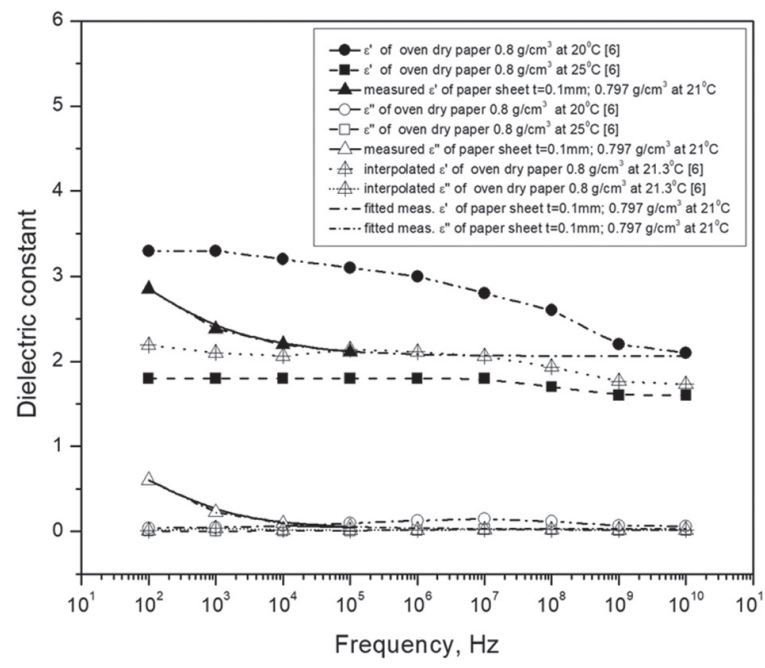

Fig. 10. Measured, linear interpolated and fitted dielectric constant (real and imaginary part) as a function of frequency for $0.1 \mathrm{~mm}$ paper sheet and measured dielectric constant of the oven-dry sheet paper [6].

Measured data as well as measured data from the literature are fitted and inserted in Figures 9 to 11. Exponential fitting of results was performed according to the formula:

$$
y=A \exp (-x / t)+y_{0}
$$




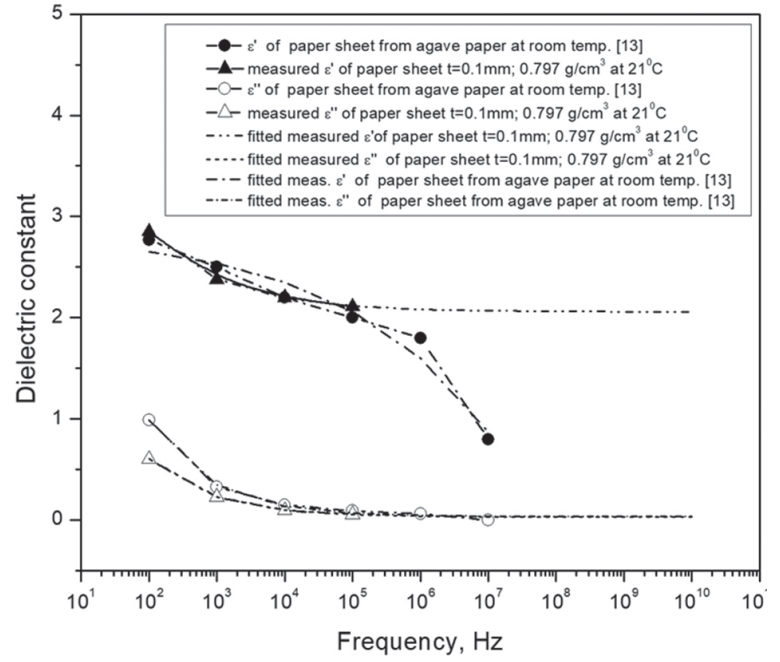

Fig. 11. easured, linear interpolated and fitted dielectric constant (real and imaginary part) as a

function of frequency for $0.1 \mathrm{~mm}$ paper sheet and measured dielectric constant of the papers with fibers from agave [13].

Maximum deviations from the fitted result of measurement and measurement results according to the literature at the frequency of interest $(2 \mathrm{GHz})$ are presented in Table 9.

Table 9. Relative errors of the real and the imaginary part of the dielectric constant of fitted measured results and measured results from literature

\begin{tabular}{|ccc|}
\hline Dielectric constant & $\begin{array}{c}\text { Real part error } \\
\%\end{array}$ & $\begin{array}{c}\text { Imag. part error } \\
\%\end{array}$ \\
\hline Tangential oak paper [4] & -5.86 & +79.85 \\
\hline Dry-oven paper [6] & -17.24 & -49.02 \\
\hline Agava paper [13] & - & +11.28 \\
\hline
\end{tabular}

The deviations of the real part of the dielectric constant do not exceed $18 \%$, while the deviations of the imaginary part are significantly higher. This can be explained by the very low values of the imaginary part and hence the greater probability of measurement and equipment inaccuracy. Furthermore, it is highly likely that the exponential fitting model is not appropriate for an area of about $2 \mathrm{GH}$ for the imaginary component of the dielectric constant.

\section{CONCLUSION}

In this paper, the parallel plate method is used to measure capacitor parameters with paper as a dielectric.

Based on the measurement, in the frequency range from $100 \mathrm{~Hz}$ to $100 \mathrm{kHz}$, the values of the real and the imaginary part of the dielectric constant of paper are calculated. Furthermore, the fitting of measured data was made by using the exponential function for the entire range of frequencies of interest (from $100 \mathrm{~Hz}$ to $10 \mathrm{GHz}$ ). The obtained values are compared with linear interpolated and exponential fitted values of different paper of the same density, temperature and initial values of the dielectric parameters at the frequency range from $100 \mathrm{~Hz}$ to $10 \mathrm{GHz}$ from the available literature. This comparison showed relatively small deviations of the real part of the dielectric constant of up to $17.5 \%$. Bigger deviations of the imaginary part of the dielectric constant are the result of very low measured values as well as the imprecision of the measured equipment and the inadequacy of the exponential fitting in that frequency bandwidth. The measured values of the dielectric constant and the loss factor correspond well to the measurements in the literature. The data thus obtained are necessary for the simulation and measurement of the reflection coefficient of the antenna aperture with a radom made of materials of similar dielectric characteristics such as paper and paper-based materials. Important applications of paper could be shown as dielectric materials in the construction of radomes. This will be further elaborated in our future work related to this paper.

\section{REFERENCES}

[1] P. Debye, "Polar molecules", Chemical Catalog Company, 1929.

[2] C. Skaar, "The dielectric properties of wood at several radio-frequencies", Technical Bulletin, Vol. 69, 1949.

[3] K. Kroner, L. Pungs, "Dielectric loss factor in natural wood at high frequencies", Holyforsch., Vol. 7, No. 1, 1953, pp. 12-18.

[4] W. L. James, "Dielectric properties of wood and hard board: variation with temperature moisture and grain", U.S. Department of Agriculture Forest Service, Forest Products Laboratory Madison, Wisconsin, USA, 1975.

[5] M. G. Gaikwad, Correlation of positronium lifetimes and dielectric constants in organic liquids, Savitribai Phule Pune University, Pune, India, PhD Thesis, 1981.

[6] G. I. Torgovnikov, "Dielectric Properties of Wood and Wood-Based Materials", $1^{\text {st }}$ Ed., Springer Verlag, 1993.

[7] U. W. Kempf, "Microsphere containing circuit board paper", US6042936 patent FlberMark, 1997.

[8] T. T. Grove, M. F. Masters, R. E. Miers, “Determining dielectric constants using a parallel plate capaci- 
tor", American Association of Physics Teachers, Vol. 73, No. 1, 2005, pp. 52-56.

[9] M. S. Venkatesh and G.S.V. Raghavan, "An overview of dielectric properties measuring techniques", Canadian Biosystems Engineering, Vol. 47, 2005, pp. 15-30.

[10] S. Ganchev, "Materials Measurement Techniques \& Applications", Americas TM Contact Center, Agilent Technologies, USA, 2006.

[11] R. E. Mark, C. Habeger, J. Borch, M. B. Lyne, "Handbook of Physical Testing of Paper: Volume 1 and 2", 2ndEd., CRC Press, 2001.

[12] P. Sirvio, "Electrical and Dielectric Properties of Uncoated and Coated Wood-Free Paper for Electrophozography", Faculty of Science and Engineering Ĺbo Akademi University Abo, Turku, Finland, PHD Thesis, 2016.

[13] H. El Omari, A. Zyane, A. Belfkira, M. Taourirte, F. Brouillette, "Dielectric Properties of Paper Made from Pulps Loaded with Ferroelectric Particles", Journal of Nanomaterials, Vol. 2016, 10 pages.
[14] G. L. Johnson, Solid State Tesla Coil, http://hotstreamer.deanostoybox.com/TeslaCoils/OtherPapers/GaryJohnson/tcchap1.pdf (accessed: 2018)

[15] G. J. Meyer, Polyurethane Foam: Dielectric Materials for Use in Radomes and Other Applications, General Plastics Manufacturing Company, https:// www.generalplastics.com/wp-content/uploads/2016/12/White-Paper-PU-Foam-DielectricMaterials-for-Use-in-Radomes-and-Other_Applications.pdf (accessed: 2018).

[16] O. V. Tereshchenko, F. J. K. Buesink, F. B. J. Leferink, "An overview of the techniques for measuring the dielectric properties of materials", Proceedings of the 2011 XXX ${ }^{\text {th }}$ URSI General Assembly and Scientific Symposium, Istanbul, Turkey, 13-20 August 2011, pp. 1-4.

[17] S. Rupcic, Z .Sipus, V. Mandric, "Input admittance of Circular Waveguide Opening Mounted on Dielectric-Covered Grounded Spherical Surface", Proceedings of the International Symposium ELMAR, Zadar, Croatia, 28-30 September 2012, pp. 317-320. 